\title{
Freshmen or Pre-graduates, Who Need More Attention?-Mental Health Changes From Chinese Freshmen to Pre-graduates
}

\author{
Haiping Wanga, Yan Ruth Xiab, Xiaoyun Zhangb
}

\begin{abstract}
First year of college was found to be the most challenging and stressful year due to the transition from home to school and the adjustment to new life, however, others reported that pre-graduates suffered from more mental problems under the pressure of job-hunting and uncertainty of future. This study sought to examine mental health development measured with University Personality Inventory (UPI) among Chinese college students and its relationship with family factors (family income, family residence, and sibling status) with a longitudinal design. Data of 390 Chinese college students were collected at their first and the third year of college period. The results showed that Chinese college students' overall mental health declined in the third year than in the first year. Urban students showed a more rapid increase in physical symptoms from the first year to the third year than rural students. The results indicated that psychological intervention should be extended to students facing graduation, especially those from urban area.
\end{abstract}

\section{Keywords}

College students, mental health, longitudinal study

College students' mental health has received increased attentions in recent years. Research shows that college students frequently have more complex problems today than they did over a decade ago (Benton et al. 2003). China has approximately 23 million college students, the largest population in the world (Yang 2005), among which, more than ten percent undergraduate students were estimated to suffer from mental and emotional problems (Zhang, Zhu, and Li 2003; Ni, Dai, and Shen 2007).

It was found that the first year of college was to be the most challenging and stressful year due to the transition from home to school and the adjustment to new life (Verger et al. 2009). Ross and colleagues (1999) examined freshmen's stress and found that new responsibilities such as adjusting to new social environment and keeping high level of academic performance brought much pressure to the freshmen. Hudd et al. (2000) explained that this experience of stress might be due to the departure from families and old friends. In China, first year college life was also identified as the period with most psychological risks (Liu and $\mathrm{Xu}$ 2003).

However, another studies yielded different result, which found that freshmen were actually happier and had less mental problems than junior

\footnotetext{
aEast China Normal University, China bUniversity of Nebraska-Lincoln, USA

\section{Correspondent Author:}

Haiping Wang, No. 103, 585 Binhu Road, Songjiang District, Shanghai, China, 200016
} 
students due to the stress from job hunting before graduation (Deng and Zheng 2004). Feng and Huang (2009) examined college students' mental health with SCL (Symptom Checklist) scale, and found that senior college students reported more mental symptoms than freshmen on somatization and depression sub-scales.

It is obvious that the findings regarding to which group of students were more mentally risky were contradictory. However, the research targeted on this issue is sparse and more research is called to provide solid information, because the clarification of this issue had practical implications for Chinese school counselors and educators as well as policy makers. In China, university educators and counselors are responsible for both educating psychological knowledge to students and providing counseling to them, every year, they conducted screening test for freshmen in order to identify psychologically-risky student, and supervise their development when they are on campus. This strategy was set based on research which showed freshmen were the most risky students as they were transiting from high school to university. However, if studies showed junior and senior students have more mental problems, university educators and counselors may need to adjust their reach-out strategy to pay more attention to junior and senior students.

The current study is aimed to add to the literature through examining Chinese college students' mental development from year one to the end of year three (as senior students were out for job hunting and hard to recruit) with a longitudinal study, in order to test whether students overall mental health status declined before graduation. In addition, to examine how family play a role in students' mental development, three family factors including family residence, family income, and sibling status were involved.

\section{LITERATURE REVIEW}

Recent literature related to mental health needs of today's college students reported that a great number of students are coping with depression, anxiety, and other major mental health challenges (Kitzrow 2003; Kadison and DiGeronimo 2004). In China, most studies on this issue showed similar findings. Jiang (2004) conducted a study examining freshmen's psychological problems. In this study, 1,351 freshmen were surveyed. The results showed that $11.91 \%$ of the freshmen reported serious mental health problems, and $26.15 \%$ of them suffered moderate mental health problems. Another study examined mental health status of 430 undergraduate students in a Hangzhou business college. This study found that $22 \%$ of the students had mental health issues, with $9.8 \%$ reporting being anxious, $8.6 \%$ being obsessive, and $8.6 \%$ experiencing other disturbances (Wang et al. 1992). Wang and Fan (2002) conducted a survey among college students in Beijing, which showed that $16.5 \%$ college students in this sample had mental health problems.

There are several major approaches to understand the etiology and treatment of mental health: (1) the ecology theory; (2) the biological approach; (3) psychological approach and sociological approach; and (4) the biopsychosocial theory. Among them, Brofenbrenner (1986)'s ecological theory is the most leading theory in understanding individual' mental problems. Ecological model discussed the complex and numerous sources of potential stress or security in the life of individual. Family, school, and peers are examples of microsystem level factor that directly influence individual, while macrosystem level factors (e.g., societal values, economic circumstances) are indirect influences.

According to Brofenbrenner (1986)'s theory, family as a context for human development, is essential to the healthy development of a young person. Family contexts including family income, living in rural or urban setting and being the old child or not, influence the psychosocial development, school accomplishment, and career development of a young person. In one 
study of Chinese college students' personality disorder, researchers found that students from rural areas scored higher than those from urban areas on the schizoid, schizotypal, narcissistic, avoidant, compulsive-obsessive, passive-aggressive, and depressive personality disorder scales, and lower on the paranoid and dependent scales (Huang et al. 2007). Jiang (2004) found that the significant differences existed between students from rural place and urban place. The students from rural areas reported more mental health problems than the students from urban areas. Another study found the similar results that students from the countryside had more psychological problems than the students from cities (Wang and Fan 2002).

Another family factor which might contribute to the development of students' mental health is sibling status. From the perspective of deprivation theory, the only child was seen as selfish, lonely, or maladjusted than children with siblings since they lack sibling support and lack the experience to live with and learn from siblings (Thompson 1974; Falbo 1977). In contrast, uniqueness theory contends that the only child tends to be happier than the child with siblings (Falbo 1981). Compared with children with siblings, only children might obtain more attentions, loves, and materials from parents and relatives. They appear to be secure, confident, and ambitious. Falbo and Polit (1986) conducted a quantitative meta-analysis on only child research, and their results contradicted both deprivation and uniqueness mechanism. Across the areas of achievement, intelligence, sociability, character, and adjustment, only children were not reliably different from firstborns or those from small families (i.e., two-child families). However, later empirical studies still yielded results showing only-child is significantly different from children with siblings. Kitzmann, Cohen, and Lockwood (2002) found that the only child was similar to classmates in terms of number of close friendships and friendship quality, but was less liked by classmates as a group.
The only child was more likely to be both victimized and aggressive in the peer group, suggesting that having a sibling may be helpful for learning to manage interpersonal conflict. Yang et al. (1995) found that compared with children with siblings, the only child reported significant lower levels of fear, anxiety, and depression, regardless of sex or age. Another study compared the status of mental health with character of the singleton and non-singleton college students, and found the singletons have better sleep and fewer psychosomatic symptoms than the non-singletons (Dai, Feng, and Yu 2005). In China today, more and more only children entered into colleges. Research for this population is in need to understand how well they fare academically and psychosocially.

Family income plays an important role in sustaining health and well-being of family members. There is a growing literature showing that low family income is associated with worse child mental health (e.g., Merten and Wickrama 2004; Rutter 2003; Strohschein 2005). The mechanism by which family income transferred to child mental health was also studied by recent researchers. Reduction in family income leads to a worse child mental health through increased economic pressure and negative changes in parental mental health, marital interaction, and parenting quality (Propper, Rigg, and Burges 2007; Solantaus, Leinonen, and Punamäki 2004). How poverty and family resources are related to college students' mental health has not been studied. Although Chinese government provides financial aids to Chinese students from low income families, tuition and living expenses still pose a huge financial burden to these families.

Under the old higher education system, college students enjoyed uniform benefits and opportunities. The differences in family contexts may play a bigger role in college students' mental health and social adjustment than it did in the past. With the implementation of new policies, resources available to 
individual student vary greatly because of differences in family backgrounds. How do family factors such as income, residency (rural vs. urban), and sibling status (the only child vs. child with siblings) influence Chinese college students' mental health? By far, studies of college students' mental health are mainly cross-sectional investigations. It is not clear how well they are doing throughout the four years of their study. To fill the gap in knowledge, this study examined Chinese college students' mental health status from the first year of college to the third year with a longitudinal design, and investigated how family income, residence, and sibling status influenced college students' mental health.

\section{METHOD}

\section{Sample, Recruitment, and Procedure}

College students who were enrolled in a fall semester at a comprehensive Chinese university in southern China were invited to participate in a screening survey in their first year and again the third year. The students at this university came from all over the country. The university's support was secured and a list of students' email addresses was obtained from the Registrar and Record Office. The survey was administered on-line. Data of 390 participants who were surveyed both first year and third year of college were collected. The participants were 317 male (81.3\%) and 73 female (18.7\%), representative of the gender distribution of the university enrollment which was 8,019 male $(78.2 \%)$ and 2,999 female (22.8\%). They were between the ages of 16 and 23 years $(M=19.4, S D=.87)$. Eighty-three percent of students had siblings and $16 \%$ of students were the only child in the family. Participants lived in rural areas, $49.6 \%$ $(N=194)$, and urban areas, $14.8 \%(N=58)$ respectively. Of all 390 students, $23 \%(N=90)$ were from very low income (less than 2,000 yuan), about $19 \%(N=74)$ from low income $(2,000-5,000$ yuan $)$,
23.3\% $(N=91)$ from medium income $(5,000-10,000$ $y u a n)$, and $34.5 \%(N=135)$ from high income (above 10,000 yuan), respectively.

\section{Instruments and Measures}

The survey instrument was adapted from University Personality Inventory (UPI) (Niu et al. 2000). It was first created by Japanese scholars and adapted to assess Chinese college students. UPI was a checklist of physical symptoms, emotional disturbance, and difficulty in social competence. It was originally used as a screening tool to quickly identify college students who experience physical and psychosocial symptoms. The survey questionnaire for this study consisted of three sections. The first section collected demographic information of age, gender, student status (i.e., freshman or graduate); the second section included 60 binary questions that assess the symptom occurrence; and the third section asked four open-ended questions for further and in-depth information about students' perceptions of their physical and mental health, attitude toward mental health services, and mental health history. An answer of "yes" scored 1 and "no" scored 0 . All the points were summed up to generate an individual response score.

Dependent variables of this study were overall score and the physical symptom, emotional disturbance, and social incompetence. Each measure was the sum scores of items assessing the associated symptoms with higher score indicating more symptoms. The independent variables were three family factors including, family income, family residence (rural vs. urban), sibling status (the only child vs. child with siblings).

\section{RESULTS}

For overall UPI score of first year and third year, the paired t-test was analyzed. The result indicated a statistically significant difference between the UPI score of first year and third year $(t(389)=-9.62$, $p<.001)$. UPI score of the third year reported was 
significantly higher than the score of the first year (see Table 1 for detailed descriptive statistics).

A multivariate analysis was performed on the three subscales of UPI: (1) physical symptoms; (2) emotional disturbance; and (3) social incompetence, to provide a profile of Chinese college students' overall well-being. The grouping variable was residence - students from urban area and rural area. The between-subject main effect of residence was not significant, $\lambda=.971, F(3,248)=2.44, p>.05$. The within-subject main effect of time was statistically significant, $\lambda=.82, F(3,248)=18.04, p<.001$, suggesting the change over time in the scores of UPI. Univariate tests were followed. The Bonferroni adjustment was used for controlling Type I error $(\alpha=.05 / 3=.017)$. The main effect of time was significant for all three subscales of UPI: for physical symptoms, $F(1,250)=27.77, p<.001$; for emotional disturbances, $F(1,250)=30.83, p<.001$; for social competence, $F(1,250)=50.53, p<.001$. The interaction effect of time and residence was significant, $\lambda=.945, F(3,248)=4.79, p<.01$ (see Table 2 for detailed descriptive statistics).

In the univariate follow-up, the interaction effect was only significant on the subscale of physical symptoms, $F(1,250)=13.94, p<.001$, after the Bonferroni adjustment for controlling Type I error rate $(\alpha=.05 / 3=.017)$ (see Figure 1 for the effect).

Two other multivariate analyses were performed on the three subscales of UPI, with sibling status and family income as the grouping variable. There was no significant between-subject main effect of sibling status, $F(3,386)=.54, p>.05$. No interaction effect between time and sibling status was observed, either, $F(3,386)=1.36, p>.05$. There was also no significant between-subject main effect of family income, $F(3,372)=1.32, p>.05$, and no significant family income and time interaction effect, $F(3,372)$ $=.42, p>.05$. Mauchly's Test of Sphericity was non-significant in all the three subscales of UPI. The assumption of Sphericity was not violated.

\section{DISCUSSIONS}

\section{Mental Health Development}

The results showed that college students reported higher UPI total scores in the third year, which suggested they had more mental problems than in their freshman year. Students experienced more physical and psychological symptoms, more emotional disturbance, and felt more incompetent during the third year. This is consistent with the findings that freshmen felt happier than juniors (Deng and Zheng 2004).

Colleges play a role of transition for an individual from school to society. Freshmen in college try to adapt to college life and adjustment is critical in this year. During the second and third year, students shift their energies to emotional and relational development through involving in college life. During this period, self-development and self-growth become more important. Striving to obtain good academic performance, get outside-campus intern oppurtunities, and work to solve financial strains pressured today's college students (Kadison and DeGeronimo 2004).

In the recent reform of Chinese higher education, financial responsibility and job security are shifted from the government to individual/family accountability. China completely released the authority of assigning jobs for college students in 2003 (Yang 2005). Since then, college students attain freedom to choose their own jobs. However, this policy also means that the government no longer guarantees jobs for students. College graduates have to face the stress of finding job on their own. Furthermore, in order to provide opportunities of higher education for more high school graduates, Chinese universities began to increase enrollment since 1999 (Yang 2005). The enrollment has increased by 4.7 times in six years. Although the job market for college students has been growing at the same time due to the economic booming, it becomes increasingly competitive to get a well-paid job. Feeling uncertain about future, many of them 
Table 1. Means and Standard Deviations on Overall Scores and Three Subscale Scores by Time

\begin{tabular}{llllllllll}
\hline & \multicolumn{2}{c}{ Overall } & \multicolumn{2}{c}{ Physical } & \multicolumn{2}{c}{ Emotional } & \multicolumn{2}{c}{ Social } \\
\cline { 2 - 10 } & $M$ & $S D$ & $M$ & $S D$ & $M$ & $S D$ & $M$ & $S D$ \\
\hline Time & & & & & & & & \\
\hline & Year 1 & 8.65 & 7.30 & 1.85 & 1.96 & 3.39 & 2.98 & 3.42 & 3.36 \\
& Year 3 & $12.58^{* * *}$ & 8.51 & $2.43^{* * *}$ & 2.20 & $4.77^{* * *}$ & 3.65 & $5.39^{* * *}$ & 3.75 \\
\hline
\end{tabular}

Note: ${ }^{*} p<.05,{ }^{* *} p<.01,{ }^{* * *} p<.001$.

Table 2. Means and Standard Deviations for Total Scores of the Three Subscales by Residence in Year 1 and

Year 3

\begin{tabular}{llccccccc}
\hline & \multicolumn{3}{c}{ Rural } & \multicolumn{3}{c}{ Urban } \\
\cline { 2 - 10 } & \multicolumn{3}{c}{ Year 1 } & & Year 3 & & Year 1 & \multicolumn{2}{c}{ Year 3 } \\
\cline { 2 - 10 } & $M$ & $S D$ & $M$ & $S D$ & $M$ & $S D$ & $M$ & $S D$ \\
\hline Physical & 2.13 & 2.15 & 2.39 & 2.19 & 1.34 & 1.54 & $2.88^{* * *}$ & 2.61 \\
Emotional & 3.79 & 3.14 & 4.91 & 3.69 & 2.40 & 2.20 & 4.33 & 3.92 \\
Social & 3.79 & 3.56 & 5.33 & 3.82 & 2.67 & 2.95 & 5.23 & 3.67 \\
\hline
\end{tabular}

Note: ${ }^{*} p<.05,{ }^{* *} p<.01,{ }^{* * *} p<.001$.

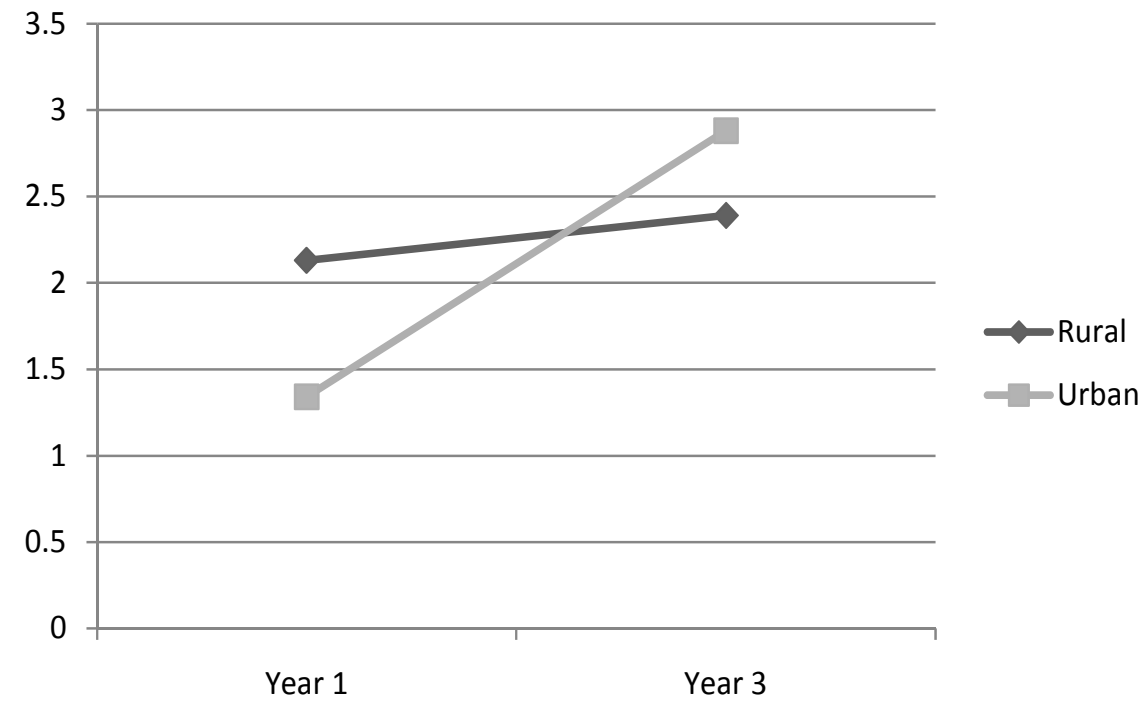

Figure 1. Profile of Symptoms Means From Year 1 to Year 3 by Residence.

are worried. With the approaching of graduation, students may become more stressed.

Traditionally, Chinese parents invest heavily in their child's learning, believing college education will give them a future job. While the system is changing, their expectation remains the same and may be unrealistic. This can exacerbate students' stress and anxiety because they do not want to disappoint their parents. Depression occurs when reality does not match their expectations.

\section{Influences of Family Factors}

Among the three family factors, only family residence has a significant effect on students UPI scores. Out of 
our expectation, urban students showed a more rapid increase in physical symptoms from the first year to the third year than rural students. We expected that urban students should adjust better to the college life and feel happier than rural students because urban students, in general, have more resources to turn to if needed. Why Chinese urban students reported worsen physical health remains unclear. It is possible that rural students who grew up in a more traditional environment were both less aware of symptoms; in particular, psychosomatic symptoms, and less open about their symptoms. Another explanation is that rural students can always go back to farming if they cannot find a job while urban students do not see and have it as an option. Richardson's resiliency theory (2002) may also offer a possible explanation. Rural students who experienced a bigger adjustment from farm to college campus in the first year attained more capability of resilience from adversity situation.

The result about sibling status is not consistent with a previous study (Yang et al. 1995), in which, researchers found that the only child reported significant better mental health than the one with siblings. They suggest that the only child perceives more expectation from parents whereas parents with more children distribute their expectation to every child so that those with siblings may feel less pressure from parents. Research is needed to further understand the effect of sibling status on the young adults.

The present study showed that family income was not significantly related to any outcomes. We hypothesized that after China implemented the new tuition policy (Zhou 2007), low-income college students might be impacted by the high financial burden. It may be that Chinese parents were absorbing the economic burden while urging their college students to focus on learning. These students did not report experiencing the psychological distress. It is also possible that most rural students enrolled in college were from the well-to-do families and those from the families with financial difficulty might not make it to college even if they were academically eligible. Furthermore, the influence of family income depends on how the family perceives and translates the available resources into positive experience (Zeitlin et al. 1995).

\section{CONCLUSIONS}

Two main implications could be derived from the current study for Chinese college and university educators and counselors. One is to extend psychological intervention to students facing graduation. Under traditional education policy, first year college life was identified as the period with most psychological risks (Liu and Xu 2003), and educators put more emphasis on the intervention of freshmen's adjustments to college life. However, with the new policies, junior and senior students are facing more stress and need more help. The other one is that more attention needs to be paid to urban students. Traditional ideas thought rural students needed more care due to the limited resources available to them, but facing the highly competitive job market, urban students seem struggled more with the stresses and therefore need more psychological help.

The findings from the current study need to be interpreted within its limitations. As this sample consists of Chinese college students from one university in southern China, it was not representative for all Chinese college students. As a result, further research with diverse demographic and geographical boundaries should be conducted to provide evidences for understanding today's college students' mental health. Additionally, the current study only focused on the examination of the roles of several family characteristics on college students' mental health, further research involving other factors such as campus life events and student personality should also bring valuable information on this issue. 


\section{References}

Benton, S. A., J. M. Robertson, T. Wen-Chih, F. B. Newton, and S. L. Benton. 2003. "Changes in Counseling Center Client Problems Across 13 Years." Professional Psychology: Research and Practice 34(1):66-72.

Bronfenbrenner, U. 1986. "Ecology of the Family as a Context for Human Development: Research Perspectives." Educational Psychology 22:723-742.

Dai, W. M., S. L. Feng, and L. Q. Yu. 2005. "The Comparison of the Status of Mental Health of the Singleton and Non-singleton College Students." Chinese Mental Health Journal 19(4):256-258.

Deng, L. and R. Zheng. 2004. "Affect Variables and Mental Health in College Students." Chinese Mental Health Journal 18(1):58-60.

Falbo, T. 1977. "The Only Child: A Review." Journal of Individual Psychology 33(1):47-61.

—. 1981. "Relationships Between Birth Category, Achievement, and Interpersonal Orientation." Journal of Personality and Social Psychology 41:121-131.

Falbo, T. and D. F. Polit. 1986. "Quantitative Review of the Only Child Literature: Research Evidence and Theory Development.” Psychological Bulletin 100:176-189.

Feng, Z.-F. and Z.-S. Huang. 2009. "Assessment of the Result of SCL-90 From Freshmen and Seniors." Journal of Langfang Teachers College (Natural Science Edition) 9(4):48-49.

Huang, X., H. Ling, B. Yang, and G. Dou. 2007. "Screening of Personality Disorders Among Chinese College Students by Personality Diagnostic Questionnaire-4+." Journal of Personality Disorders 21(4):448-454.

Hudd, S. S., J. Dumlao, D. Erdmann-Sager, D. Murray, E. Phan, N. Soukas, and N. Yokozuka. 2000. "Stress at College: Effects on Health Habits, Health Status and Self-esteem." College Student Journal 34(2):217-227.

Jiang, F. L. 2004. "A Comparison and Analysis of Results of UPI Surveys of Freshmen at Local Colleges." Psychological Science (China) 27(2):483-486.

Kadison, R. and T. F. DiGeronimo. 2004. College of the Overwhelmed: The Campus Mental Health Crisis and What to Do About It. San Francisco: Jossey-Bass.

Kitzmann, K., R. Cohen, and R. Lockwood. 2002. "Are Only Children Missing Out? Comparison of the Peer-Related Social Competence of Only Children and Siblings." Journal of Social and Personal Relationships 19(3):299-316.

Kitzrow, M. A. 2003. "The Mental Health Needs of Today's College Students: Challenges and Recommendations." NASPA Journal 41(1):165-179.

Liu, X. and H. Xu. 2003. "Review on Study of Mental Health of College Students in China During Current 15 Years." Chinese Mental Health Journal 17(2):124-126.

Merten, M. J. and K. Wickrama. 2004. "Influence of Community and Family Adversities on Adolescent Mental Health: Mediating Role of Precocious Development." Presented at the Annual Meeting of the American Sociological Association, August 14, Hilton San Francisco $\&$ Renaissance Parc 55 Hotel, San Francisco, CA.

Ni, Y., J. Dai, and X. Shen. 2007. "Mental Health Status of Civilian Aviator Students." Chinese Mental Health Journal 21(7):473-475.

Niu, L., M. Matsui, N. Yamashita, and M. Kurachi. 2000. “The Relationship Between University Personality Inventory (UPI) and Minnesota Multiphasic Personality Inventory (MMPI)." Seishin Igaku (Clinical Psychiatry) 42(8):827-833.

Propper, C., J. Rigg, and S. Burgess. 2007. "Child Health: Evidence on the Roles of Family Income and Maternal Mental Health From a UK Birth Cohort." Health Economics 16(11):1245-1269.

Richardson, G. E. 2002. "The Metatheory of Resilience and Resiliency." Journal of Clinical Psychology 58(3):307-321.

Ross, S. E., B. C. Niebling, and T. M. Heckett. 1999. "Sources of Stress Among College Students." College Student Journal 13:312-317.

Rutter, M. 2003. "Poverty and Child Mental Health: Natural Experiments and Social Causation." JAMA: Journal of the American Medical Association 290(15):2063-2064.

Solantaus, T., J. Leinonen, and R. Punamäki. 2004. "Children's Mental Health in Times of Economic Recession: Replication and Extension of the Family Economic Stress Model in Finland." Developmental Psychology 40(3):412-429.

Strohschein, L. 2005. "Household Income Histories and Child Mental Health Trajectories." Journal of Health and Social Behavior 46(4):359-375.

Thompson, V. D. 1974. "Family Size: Implicit Policies and Assumed Psychological Outcomes." Journal of Social Issues 30(4):93-124.

Verger, P., J. Combes, V. Kovess-Masfety, M. Choquet, V. Guagliardo, F. Rouillon, and P. Peretti-Wattel. 2009. "Psychological Distress in First Year University Students: Socioeconomic and Academic Stressors, Mastery and Social Support in Young Men and Women." Social Psychiatry and Psychiatric Epidemiology 44(8):643-650.

Wang, J. and F. Fan. 2002. "The Mental Health State of College Students in Beijing." Chinese Mental Health Journal 16(5):331-333.

Wang, X., J. Liao, G. Fan, and B. Feng. 1992. "Mental Health Survey of Undergraduate Students at the Institute of Business in Hangzhou (Abstract)." Chinese Mental Health 
Journal 6(3):108. Retrieved (http://0-search.ebscohost. com.library.unl.edu/login.aspx?direct $=$ true $\& \mathrm{db}=$ psyh $\& A N$ =1993-85960-001\&site=ehost-live).

Yang, B., T. H. Ollendick, Q. Dong, H. Xia, and L. Lin. 1995. "Only Children and Children With Siblings in the People's Republic of China: Levels of Fear, Anxiety, and Depression." Child Development 66:1301-1311.

Yang, D. P. 2005. The Largest Population of College Students in the World, the Decreasing Education Quality. Retrieved (http://education.163.com/06/0522/09/2HNFGIJ300291MU F.html).

Zeitlin, M. F., R. Megawangi, E. L. Kramer, N. D. Colletta, E. D. Babatunde, and D. Garman. 1995. Strengthening the Family-Implications for International Development. Retrieved (http://www.unu.edu/unupress/unupbooks/ uu13se/uu13se00.htm).

Zhang, A., A. Zhu, and X. Li. 2003. "Mental Health and Achievement Motivation of Undergraduate Students (Abstract)." Chinese Mental Health Journal 17(5): 342-343.
Zhou, W. 2007. New Occupational Trends of Modern College Students. Retrieved (http://www.gmw.cn/01gmrb/2007-01/ 04/content_530824.htm).

\section{Bios}

Haiping Wang, Ph.D., assistant professor, Department of Social Work, East China Normal University, China; research fields: adolescent mental health, positive developing, women study, marriage and family therapy.

Yan Ruth Xia, Ph.D., associate professor, Department of Child, Youth, and Family Studies, University of Nebraska-Lincoln, USA; research fields: child and youth development, immigrant families, stress and positive coping, marriage and family therapy.

Xiaoyun Zhang, Ph.D., Department of Child, Youth, and Family Studies, University of Nebraska-Lincoln, USA; research fields: adolescent mental health, child development, marriage and family therapy. 